\title{
Behavior of the P1.HTR mastocytoma cell line implanted in the chorioallantoic membrane of chick embryos
}

\author{
Ş.F. Avram ${ }^{1,2}$, A.M. Cimpean ${ }^{1}$ and M. Raica ${ }^{1}$ \\ ${ }^{1}$ Department of Histology, Angiogenesis Research Center, Victor Babeş University of Medicine and Pharmacy, \\ Timişoara, Romania \\ ${ }^{2}$ Department of Pharmacognosy, Victor Babeş University of Medicine and Pharmacy, Timişoara, Romania
}

\begin{abstract}
The P1.HTR cell line includes highly transfectable cells derived from P815 mastocytoma cells originating from mouse breast tissue. Despite its widespread use in immunogenic studies, no data are available about the behavior of P1.HTR cells in the chick embryo chorioallantoic membrane model. The objective of the present investigation was to study the effects of P1.HTR cells implanted on the chorioallantoic membrane of chick embryos. We inoculated P1.HTR cells into the previously prepared chick embryo chorioallantoic membrane and observed the early and late effects of these cells by stereomicroscopy, histochemistry and immunohistochemistry. A highly angiotropic and angiogenic effect occurred early after inoculation and a tumorigenic potential with the development of mastocytoma keeping well mast cells immunophenotype was detected later during the development. The P1.HTR mastocytoma cell line is a good tool for the development of the chick embryo chorioallantoic membrane mastocytoma model and also for other studies concerning the involvement of blood vessels. The chick embryo chorioallantoic membrane model of mastocytoma retains the mast cell immunophenotype under experimental conditions and could be used as an experimental tool for in vivo preliminary testing of antitumor and antivascular drugs.
\end{abstract}

Key words: P1.HTR; Mastocytoma; Chick embryo chorioallantoic membrane; Angiogenesis

\section{Introduction}

Mast cells are normal residents of tissues (1) and have been recognized as key cells of type I hypersensitivity reactions by expressing critical effector functions in classic IgE-associated allergic disorders (2). Mast cells exert distinct non-immunological functions, being involved in tissue homeostasis, fibrosis and angiogenesis. The involvement of mast cells in angiogenesis has been strongly supported by clinico-pathological (3-5) and experimental studies $(6,7)$ in different malignant and non-malignant diseases, but their role in the angiogenic process is still not well characterized. The involvement of mast cells in angiogenesis is supported by the ability of these cells to secrete growth factors and molecules that induce vascular hyperpermeability (8). Convincing data supporting a role for mast cells in tumor progression via formation of new blood vessels have accumulated $(3,4)$. On the other hand, it is not yet completely understood if mastocytoma cells have the same properties. Between 1976 and 2011, up to 15 published articles have reported the different effects of mast cells or some of their components on the chick embryo chorioallantoic membrane model regarding angiogenesis and inflammation but no chorioallantoic membrane mastocytoma model was established.

Designed by van Pel et al. (9) and Wölfel et al. (10), P1.HTR mastocytoma cells (Mouse DBA/2 mastocytoma) are a murine mastocytoma cell line derived from the P815 cell line after serial cycles of transfection. P815 cell lines offer several advantages for in vivo experimentation regarding the tumor-host relationship (11) but no data are available about the behavior of P1.HTR-transfected cells in the chick embryo chorioallantoic membrane model.

Because of the lack of data concerning the use of P1.HTR cells as an experimental tool for obtaining a mastocytoma tumor model, we proposed here to study the early and late effects of the P1.HTR cell line implanted on the chick embryo chorioallantoic membrane.

Correspondence: A.M. Cimpean, Department of Histology, Angiogenesis Research Center, Victor Babeş University of Medicine and Pharmacy, Piata Eftimie Murgu 2, Timişoara, TM 300041, Romania. E-mail: ancacimpean1972@yahoo.com 


\section{Material and Methods}

\section{Experimental study design}

The chorioallantoic membrane was prepared according to the method described by Ribatti et al. (12). Briefly, two groups of 20 White Leghorn eggs each (control group and treated group) were incubated at $37^{\circ} \mathrm{C}$ for 3 days. On the third day of incubation, 2-3 $\mathrm{mL}$ albumin was removed and a window was opened in the eggshell to observe the chick embryo's chorioallantoic membrane. The study started on day 7 of incubation by inoculation of mastocytoma cells below the chorioallantoic membrane.

\section{Cell inoculation and experiment monitoring}

We used the P1.HTR cell line, a highly transfectable variant of the P815 mastocytoma cell line (9). Cultured tumor cells were washed in Dulbecco's PBS (DPBS) and $10^{6}$ living cells in $100 \mu \mathrm{L}$ PBS were inoculated below the chorioallantoic membrane. Inoculation was performed in a blood vessel-free area of the chick embryo chorioallantoic membrane to avoid hemorrhagic events. Specimens were then carefully observed step by step at $30 \mathrm{~min}$ and at 6 and $24 \mathrm{~h}$ after inoculation by vascular network analysis using a Zeiss stereomicroscope (Germany). Pictures were captured with a Canon camera (USA) attached to the stereomicroscope.

\section{Morphology and histochemistry}

We performed in ovo staining of the specimens at 6 and $24 \mathrm{~h}$ after inoculation using Alcian blue/safran histochemistry and routine hematoxylin and eosin staining followed by immunohistochemistry for paraffin-embedded specimens collected at $24 \mathrm{~h}$ and 7 days after inoculation. Before the staining procedures, all specimens were fixed in $10 \%$ buffered formalin. Specimens collected $24 \mathrm{~h}$ postinoculation were previously fixed with $10 \%$ buffered formalin and stained in ovo with Alcian blue/safran for $15 \mathrm{~min}$ to visualize mast cells. Serial $5-\mu \mathrm{m}$ thick sections were obtained from the paraffin-embedded specimens and stained with hematoxylin and eosin for morphologic assessment. Microscopic analysis was followed by slide selection for immunohistochemistry.

\section{Immunohistochemistry}

We used a panel of vascular and mast cell markers for the immunostaining of paraffin-embedded specimens. Endothelial cells of the chick embryo chorioallantoic membrane vessels were highlighted using the FVIIIrelated rabbit polyclonal antigen (1:200 dilution, Dako, USA). Smooth muscle actin (clone 1A4, ready to use, Dako) was used to stain perivascular cells. For mast cell identification, we performed two immunohistochemical procedures using anti-mast cell tryptase antibodies (AAT1, 1:300 dilution, Dako) and anti-mast cell chymase antibodies (ready to use, polyclonal, Neomarkers, LabVision, USA). Incubation with the primary antibodies for 30 min was followed by the use of labeled streptavidin biotin complex and 3,3'-diaminobenzidine as chromogen. Nuclei were stained with modified Lillie's hematoxylin. The full immunohistochemical procedure was performed in an automated fashion using the DakoCytomation PT Link for the antigen retrieval step and DakoAutoStainer for the next steps of the immunohistochemical procedure (DakoCytomation, Denmark).

\section{Microscopic analysis}

The in ovo behavior of blood vessels and P1.HTR cells was assessed with a Zeiss Stemi DV4 SPOT stereomicroscope equipped with a Canon camera. Microscopic evaluation of morphologically, histochemically and immunohistochemically stained specimens was performed using a Nikon Eclipse E600 microscope (Japan). The Lucia G software was used for image capture and processing. We quantifed blood vessel number and morphology together with mast cell distribution and phenotype.

\section{Results}

\section{In vivo macroscopic assessment}

Inoculation of P1.HTR cells in DPBS as vehicle was performed carefully in a chick embryo chorioallantoic membrane area free of blood vessels (Figure 1A). A proper inoculation was recognized by the presence of a small bubble at the inoculation site (Figure 1B). No hemorrhagic events occurred.

Thirty minutes later, assessment of the chick embryo chorioallantoic membrane revealed vascular changes around the inoculation site. Small, perfused blood vessels oriented toward the inoculation site were found and a hyperemic reaction occurred. The development of the vascular network continued and, at $6 \mathrm{~h}$ post-inoculation, we observed a well-developed network of interconnected small blood vessels and the presence of spotted hemorrhagic areas (Figure 1C). Hemorrhagic events were persistent and became more evident $24 \mathrm{~h}$ post-inoculation together with a mature, functional vascular area with a "cobblestone-like" pattern with a high density of small, perfused interconnected blood vessels (Figure 1D).

Microscopic evaluation was first performed in in ovo fixed and stained treated and control specimens and then in paraffin-embedded morphologically and immunohistochemically stained sections.

One day after P1.HTR cell inoculation, in ovo Alcian blue/safran-stained specimens were collected, mounted on electrically charged slides and evaluated. Alcian bluestained mast cells were found as small groups along the main vessels of the chick embryo chorioallantoic membrane. Mast cell groups were surrounded by a high density of small, thin, perfused blood vessels with a "wheel spoke-like" arrangement around them (Figure 2A, red arrows). The newly formed vascular network observed 

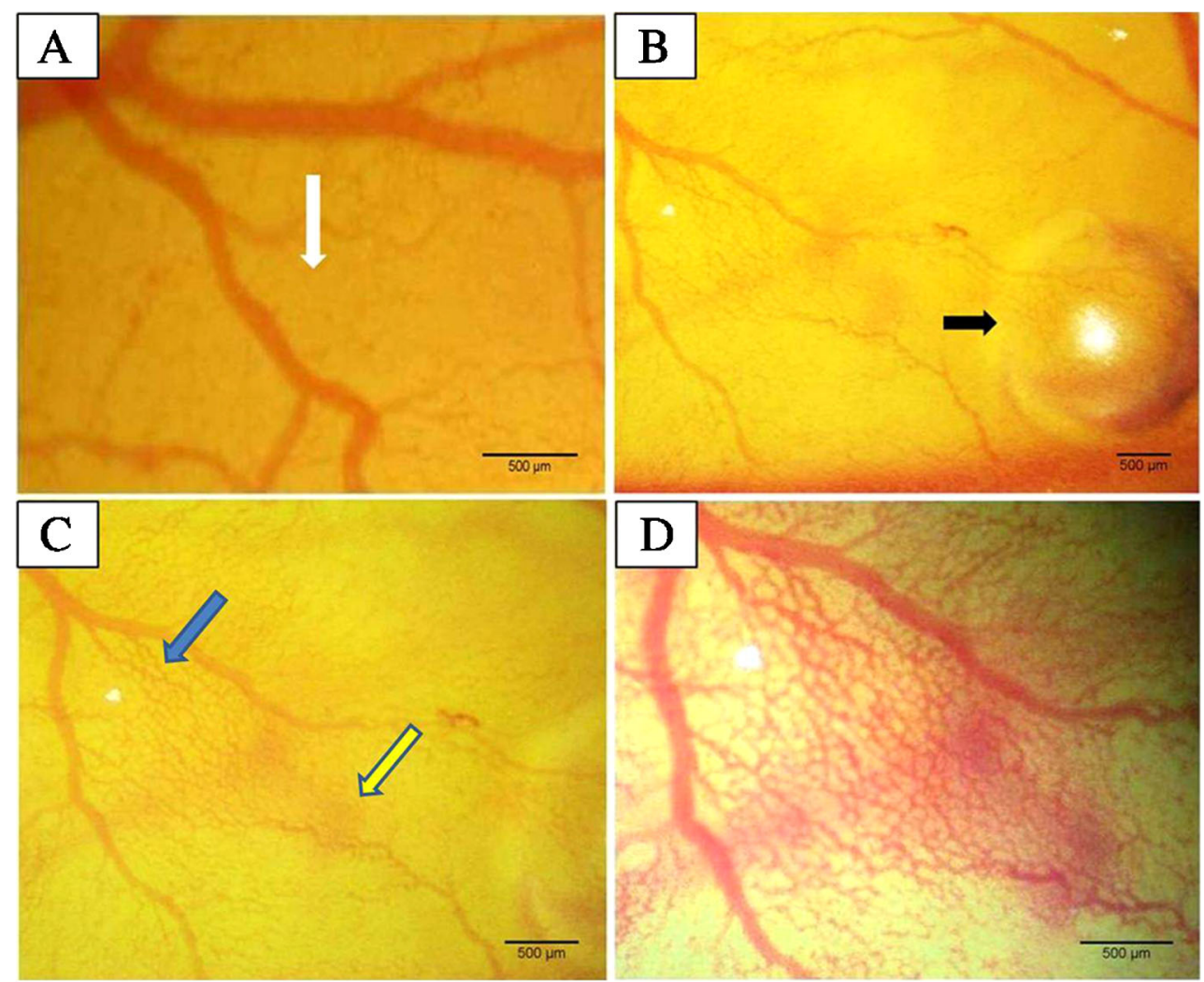

Figure 1. Inoculation site of P1.HTR cells on chick embryo chorioallantoic membrane (CAM) $(A)$. Note the blood vessel-free area between large CAM vessels (white arrow). Thirty minutes after inoculation, a small bubble persists and the surrounding vessels become more evident $(B$, black arrow), with a pronounced hyperemia (blue arrow) and spotted hemorrhagic area (yellow arrow) $6 \mathrm{~h}$ later $(C)$. "Cobblestone-like" pattern of blood vessel distribution $24 \mathrm{~h}$ post-inoculation $(D)$.

in this stage was confirmed by microscopic assessment of paraffin-embedded specimens. Hematoxylin and eosinstained sections showed an increased number of highly split perfused and unperfused blood vessels in treated specimens, $24 \mathrm{~h}$ after inoculation (Figure 2B) compared to control (Figure 2C). When we highlighted them with the FVIII-related antigen, the vascular marker was found to be expressed heterogeneously among blood vessels, being positive in most blood vessels and weakly positive or negative in others (especially unperfused and split small blood vessels). This finding suggested the presence of both immature and mature blood vessels (Figure 2D). Mature blood vessels had a continuous layer of smooth muscle actin-positive perivascular cells around the endothelial layer. Microvascular density ranged from 3 to 5 vessels/microscopic field $20 \times$ in the normal chorioallantoic membrane to 24 vessels/microscopic field $20 \times$ in treated specimens (data not shown).

Seven days post-inoculation, a well-developed macroscopically detected tumor mass was observed beneath the chorioallantoic membrane (Figure $3 \mathrm{~A}$ ). The tumor mass had a bluish-red appearance and was highly vascularized by blood vessels recruited from preexisting vessels surrounding the tumor (Figure 3B). Alcian blue/ safran staining on an uncut specimen showed a mixture of alcianophil (blue) and safraninophil (red) cells, which composed the previously described tumor mass (Figure 3C).

By immunohistochemistry, we certified tumor cell positivity for mast cell tryptase and mast cell chymase. Microscopically, the tumor mass was composed of closely packed cells with atypical nuclei and a granular cytoplasm positive for mast cells tryptase and chymase (Figure 3D). Also, tryptase- and chymase-positive granules scattered between mastocytoma cells suggested an intense degranulation process.

\section{Discussion}

The P1.HTR mastocytoma cell line, a highly transfectable variant of the P815 mastocytoma cell line, has been frequently used in tumor immunology studies in vitro (13) or in in vivo mouse models $(11,14)$. Extensive studies have been performed concerning the influence of P1.HTR cells on cellular and humoral antitumor immune 


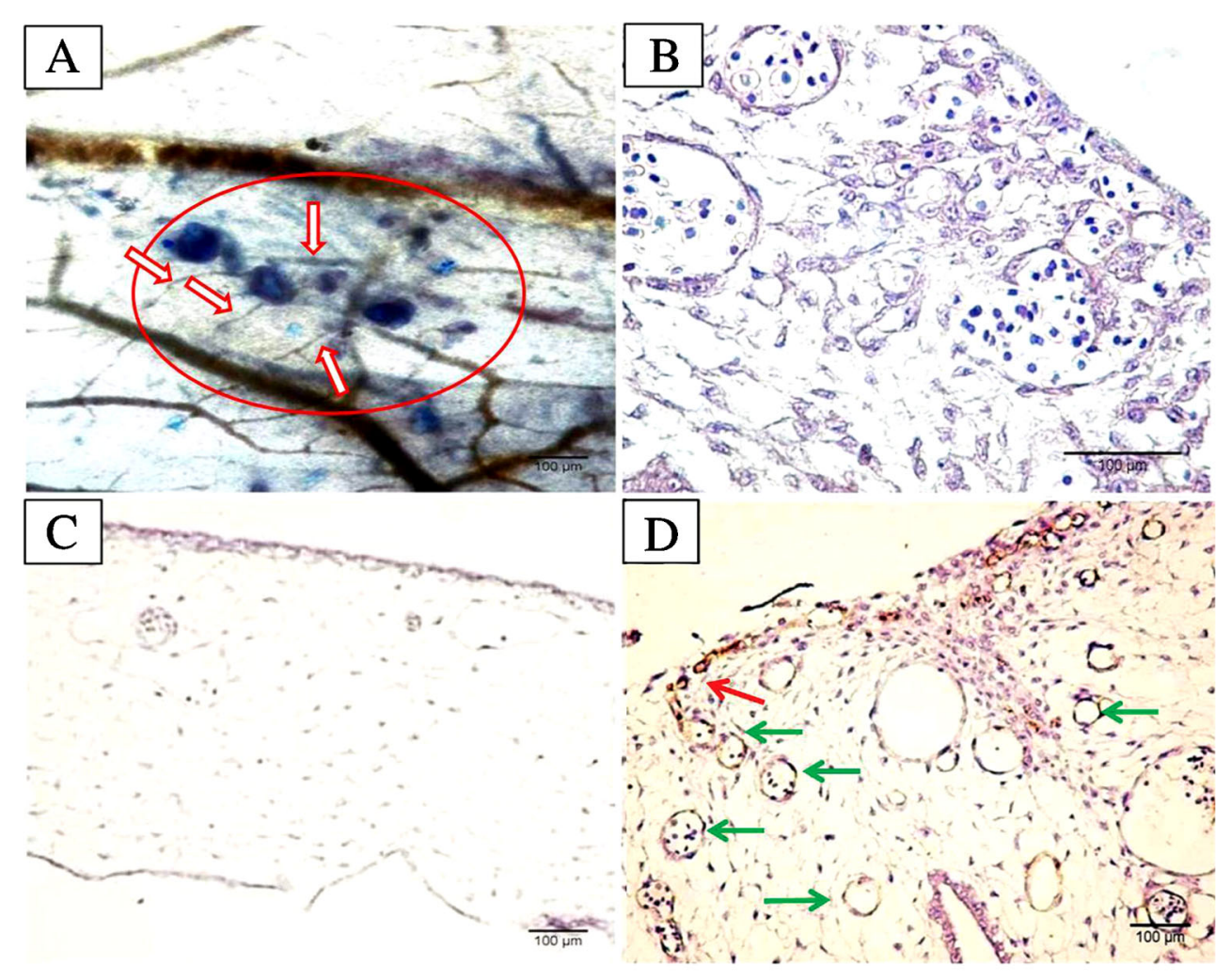

Figure 2. Assessment of chick embryo chorioallantoic membrane $24 \mathrm{~h}$ post-inoculation of P1.HTR cells. Mast cells were grouped around the main vessels (red circle) and a high density of small blood vessels convergent to mast cell clusters was observed ( $A$, white arrows, Alcian blue/safran method on uncut membrane). Histology of the chorioallantoic membrane $24 \mathrm{~h}$ post-inoculation (B). Note a high density of split small perfused and unperfused blood vessels in treated specimens compared to normal chick embryo chorioallantoic membrane $(C)$. Immunostaining with FVIII-related antigen highlighted a heterogenous distribution of a positive reaction in endothelial cells from newly formed blood vessels in treated specimens. Note the homogeneous intense positive reaction in the capillary plexuses beneath the chorionic epithelium (red arrow). Weak or moderate expression of FVIII-related antigen in the newly formed perfused and unperfused blood vessels from chick chorioallantoic membrane after mast cell inoculation (green arrows) (D).

responses $(15,16)$ but no effects on the host's vasculature have been described before. Also, except for mice, no other in vivo animal tumor model was used before for the assessment of the P1.HTR mastocytoma cell line.

Involvement of mast cells in inflammation, autoimmune disease and tumorigenesis has been extensively studied (17-19). Recently, not only symptoms produced by mast cell degranulation but mast cells themselves have been studied as potential therapeutic targets in a broad spectrum of diseases from allergy (20) to neoplastic disease $(21,22)$. However, the validation of mast cells as a therapeutic target in various diseases needs more experimental in vitro and in vivo studies.

For this purpose, we proposed here a chick embryo chorioallantoic membrane model for step-by-step evaluation of the effects of the P1.HTR mastocytoma cell line on the blood vessel network and also for the assessment of the tumorigenic potential of mastocytoma cells.

Because of its naturally immunoincompetent feature until embryonic day 17 (23) and also because of the lack of data concerning the presence of host mast cells in the chorionic mesenchyme, the chick embryo chorioallantoic membrane represents an appropriate tool for the evaluation of the effects of engrafted exogenous mast cells on both vascular network and chorionic stroma. Moreover, a direct, dynamically macroscopic and microscopic evaluation of mast cell behavior can be used to test therapy at specific time points. In the present model, we avoided the use of any carrier for engrafting mast cells and we preferred to inoculate them directly beneath the chorioallantoic membrane. Using in ovo formalin-fixed specimens and histochemistry followed by microscopic evaluation, we demonstrated a highly angiotropic effect of mast cells early after inoculation. Although several studies have reported the angiogenic effects of mast cells and/or their granules on chick embryo chorioallantoic membrane $(6,24,25)$, the angiogenic mechanism by which mast cells induce the development of new blood vessels 

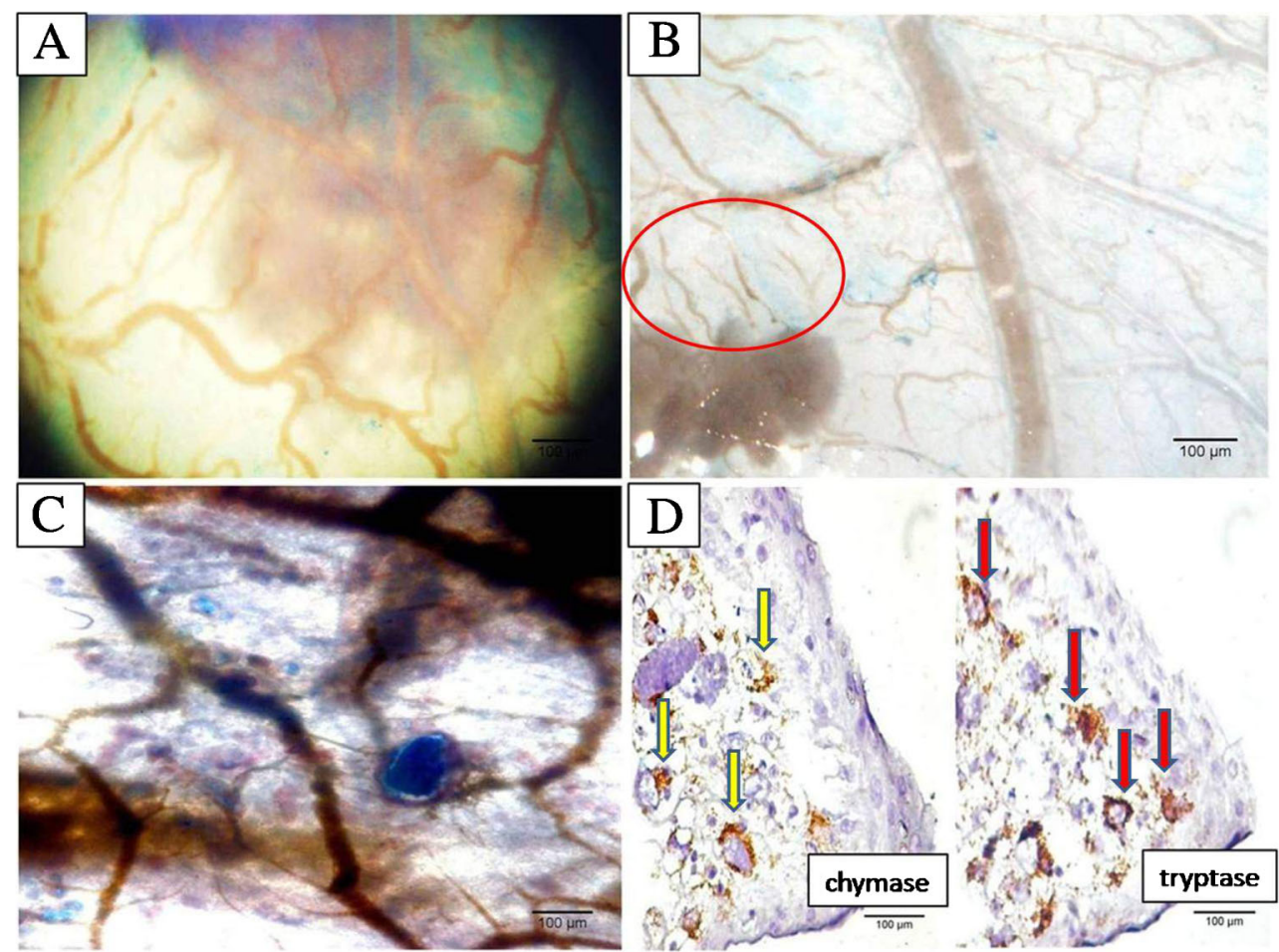

Figure 3. In ovo image of the mast cell tumor (mastocytoma) 7 days post-inoculation $(A)$. Note the disorganized vascular network and the macroscopic appearance of tumor blood vessels. "Wheel spoke-like" arrangement of blood vessels around the tumor (red circle); peritumoral blood vessels showed higher density compared to the adjacent chorioallantoic membrane vascular network $(B)$. Whole mount Alcian blue/safran staining of the chick embryo chorioallantoic membrane with a mastocytoma, before cutting $(C)$. A mixture of both safran- and Alcian blue-positive mast cells composed the mast cell tumor, surrounded by a rich network of newly formed blood vessels. By immunohistochemistry, mastocytoma tumor cells were shown to be positive for both chymase ( $D$ left, yellow arrows) and tryptase ( $D$ right, red arrows) with a granular cytoplasmic pattern.

in the chick embryo chorioallantoic membrane has not been clearly described. Evidence from our study suggests a complex mechanism of mast cell-induced angiogenesis. Early after inoculation, the presence of huge vascular hyperpermeability with spotted hemorrhages may have been due to the summative effects of both vascular endothelial growth factor and histamine, both of these factors already certified to be released from degranulated mast cells $(24,26,27)$. Twenty-four hours after inoculation, the presence of a large number of split small blood vessels in treated specimens compared to control in our study supports the hypothesis that mast cells could induce angiogenesis by activation of an intussusception angiogenic mechanism, most probably due to an interaction between surrounding stroma and mast cells.

Concerning the tumorigenic potential of P1.HTR cells, this is the first report of the development of a P1.HTR cellderived mastocytoma in the chorioallantoic membrane model. It was shown here that the mastocytoma had high angiogenic effects and its tumor cells retained their phenotype by expressing mast cell tryptase and chymase after growing on chick embryo chorioallantoic membrane.

The P1.HTR cell line is able to induce a rapid hyperpermeability of the chick embryo chorioallantoic membrane vasculature and later angiogenesis, most probably by an intussusception mechanism. Moreover, P1.HTR mast cells have a tumorigenic potential by their capacity to develop a mastocytoma consecutive to engraftment on the chick embryo chorioallantoic membrane. All of this step-by-step evidence could be used as an experimental tool for in vivo preliminary testing of antihistamine, antiallergic, antiangiogenic and antitumor drugs.

\section{Acknowledgments}

We are grateful to Diana Tătucu for her excellent technical support in the chick embryo chorioallantoic membrane processing steps. Research supported by UEFISCDI (grant IDEAS \#345/2011) of the Romanian Ministry of Education and Research. 


\section{References}

1. Metcalfe DD, Baram D, Mekori YA. Mast cells. Physiol Rev 1997; 77: 1033-1079.

2. Crivellato E, Beltrami CA, Mallardi F, Ribatti D. The mast cell: an active participant or an innocent bystander? Histol Histopathol 2004; 19: 259-270.

3. Kalra M, Rao N, Nanda K, Rehman F, Girish KL, Tippu S, et al. The role of mast cells on angiogenesis in oral squamous cell carcinoma. Med Oral Patol Oral Cir Bucal 2012; 17: e190-e196, doi: 10.4317/medoral.17395.

4. Duse AO, Ceausu RA, Mezei T, Cimpean AM, Gaje P, lonita $\mathrm{H}$, et al. Mast cells contribute to the angiogenesis in non-Hodgkin lymphoma. An immunohistochemical study based on the relationship with microvessel density. Rom J Morphol Embryol 2011; 52: 1091-1096.

5. Liu J, Zhang Y, Zhao J, Yang Z, Li D, Katirai F, et al. Mast cell: insight into remodeling a tumor microenvironment. Cancer Metastasis Rev 2011; 30: 177-184, doi: 10.1007/ s10555-011-9276-1.

6. Ribatti D, Ranieri G, Nico B, Benagiano V, Crivellato E. Tryptase and chymase are angiogenic in vivo in the chorioallantoic membrane assay. Int J Dev Biol 2011; 55: 99-102, doi: 10.1387/ijdb.103138dr.

7. Ribatti D, Crivellato E, Candussio L, Vacca A, Nico B, Benagiano $\mathrm{V}$, et al. Angiogenic activity of rat mast cells in the chick embryo chorioallantoic membrane is downregulated by treatment with recombinant human alpha-2a interferon and partly mediated by fibroblast growth factor- 2 . Haematologica 2002; 87: 465-471.

8. Norrby K. Mast cells and angiogenesis. APMIS 2002; 110: 355-371, doi: 10.1034/j.1600-0463.2002.100501.x.

9. Van Pel A, De Plaen E, Boon T. Selection of highly transfectable variant from mouse mastocytoma P815. Somat Cell Mol Genet 1985; 11: 467-475, doi: 10.1007/ BF01534840.

10. Wölfel T, Van Pel A, De Plaen E, Lurquin C, Maryanski JL, Boon T. Immunogenic (tum-) variants obtained by mutagenesis of mouse mastocytoma P815. VIII. Detection of stable transfectants expressing a tum antigen with a cytolytic $T$ cell stimulation assay. Immunogenetics 1987; 26: 178-187, doi: 10.1007/BF00365909.

11. Gajewski TF, Markiewicz MA, Uyttenhove C. The p815 mastocytoma tumor model. Curr Protoc Immunol 2001; Chapter 20: Unit.

12. Ribatti D, Gualandris A, Bastaki M, Vacca A, lurlaro M, Roncali $L$, et al. New model for the study of angiogenesis and antiangiogenesis in the chick embryo chorioallantoic membrane: the gelatin sponge/chorioallantoic membrane assay. J Vasc Res 1997; 34: 455-463, doi: 10.1159/ 000159256.

13. Lemaire $M M$, Vanhaudenarde $A$, Nizet $\mathrm{Y}$, Dumoutier L, Renauld JC. Induction of autoantibodies against mouse soluble proteins after immunization with living cells presenting the autoantigen at the cell surface in fusion with a human type 2 transmembrane protein. J Immunol Methods 2011; 367: 56-62, doi: 10.1016/j.jim.2011.02.001.

14. Kacha AK, Fallarino F, Markiewicz MA, Gajewski TF. Cutting edge: spontaneous rejection of poorly immunogenic P1.HTR tumors by Stat6-deficient mice. J Immunol 2000;
165: 6024-6028.

15. Ding LN, Isobe K, Yoshida T, Kawashima K, Nakashima I. Induction of high-grade anti-tumor immunity by use of a recombinant $\mathrm{H}-2 \mathrm{~Kb} /$ avian erythroblastosis virus erbB gene transfectant. Cancer Immunol Immunother 1990; 31: 115120, doi: 10.1007/BF01742375.

16. Amar-Costesec A, Godelaine D, Van den Eynde B, Beaufay $\mathrm{H}$. Identification and characterization of the tumor-specific P1A gene product. Biol Cell 1994; 81: 195-203, doi: 10.1016/0248-4900(94)90001-9.

17. Gilfillan AM, Beaven MA. Regulation of mast cell responses in health and disease. Crit Rev Immunol 2011; 31: 475-529, doi: 10.1615/CritRevlmmunol.v31.i6.30.

18. Carraway RE, Cochrane DE. Enhanced vascular permeability is hypothesized to promote inflammation-induced carcinogenesis and tumor development via extravasation of large molecular proteins into the tissue. Med Hypotheses 2012; 78: 738-743, doi: 10.1016/j.mehy.2012.02.021.

19. Wensman $H$, Kamgari $N$, Johansson $A$, Grujic $M$, Calounova G, Lundequist A, et al. Tumor-mast cell interactions: induction of pro-tumorigenic genes and antitumorigenic 4-1BB in MCs in response to Lewis Lung Carcinoma. Mol Immunol 2012; 50: 210-219, doi: 10.1016/ j.molimm.2012.01.009.

20. Gibbs BF, Levi-Schaffer F. H(4) receptors in mast cells and basophils: a new therapeutic target for allergy? Front Biosci 2012; 17: 430-437, doi: 10.2741/3936.

21. Chang DZ, Ma Y, Ji B, Wang H, Deng D, Liu Y, et al. Mast cells in tumor microenvironment promotes the in vivo growth of pancreatic ductal adenocarcinoma. Clin Cancer Res 2011; 17: 7015-7023, doi: 10.1158/1078-0432.CCR-110607.

22. Valent $\mathrm{P}$, Cerny-Reiterer $\mathrm{S}$, Herrmann H, Mirkina I, George TI, Sotlar K, et al. Phenotypic heterogeneity, novel diagnostic markers, and target expression profiles in normal and neoplastic human mast cells. Best Pract Res Clin Haematol 2010; 23: 369-378, doi: 10.1016/ j.beha.2010.07.003.

23. Deryugina EI, Quigley JP. Chapter 2. Chick embryo chorioallantoic membrane models to quantify angiogenesis induced by inflammatory and tumor cells or purified effector molecules. Methods Enzymol 2008; 444: 21-41, doi: 10.1016/S0076-6879(08)02802-4.

24. Detoraki A, Staiano RI, Granata F, Giannattasio G, Prevete $\mathrm{N}$, de Paulis $\mathrm{A}$, et al. Vascular endothelial growth factors synthesized by human lung mast cells exert angiogenic effects. J Allergy Clin Immunol 2009; 123: 1142-9, 1149, doi: 10.1016/j.jaci.2009.01.044.

25. Ribatti D, Crivellato E, Candussio L, Nico B, Vacca A, Roncali $\mathrm{L}$, et al. Mast cells and their secretory granules are angiogenic in the chick embryo chorioallantoic membrane. Clin Exp Allergy 2001; 31: 602-608, doi: 10.1046/j.13652222.2001.00986.x.

26. Dyduch G, Kaczmarczyk K, Okon K. Mast cells and cancer: enemies or allies? Pol J Pathol 2012; 63: 1-7.

27. Maltby S, Khazaie K, McNagny KM. Mast cells in tumor growth: angiogenesis, tissue remodelling and immunemodulation. Biochim Biophys Acta 2009; 1796: 19-26. 